\title{
What makes a good sports parent?
}

\author{
Ethics, the parent-child relationship, and sport
}

\section{Thomas Sobirk Petersen}

Two practical measures that have been introduced in an effort to stop sports parents from behaving badly will be critically discussed. The first measure is known under the slogan 'quiet weekends'. These prohibit parents from attending games in which their child is participating. Although this strategy calls attention to an important issue, it is unfair. The second, and far more elaborate, measure is to have a set of ethical guidelines informing parents how they should behave towards their child and others in the context of sport. Two central values tend to run through these guidelines: namely parental concern for the child's autonomy and parental concern for the child's well-being. These values are discussed as I apply them to cases in what can be called a grey area, where it is not obvious what is morally right or wrong. In the concluding discussion a tentative checklist will be presented which good sports parents can use when they are confronted with ethical issues.

Keywords: applied ethics, children, ethics, sport, parents

\section{Introduction}

At a youth hockey practice match in Massachusetts on 5 July 2000 ice hockey coach Michael Costing was killed by the father of one of the young players. Thomas Junta (the father in question) and Costing became involved in a deadly fight following a quarrel about rough play on ice. Junta was against rough play and Costing in favour. ${ }^{1}$ Another well-known bad sports parent is Christoph Fauviau. Fauviau drugged his sons' tennis opponents several times in tournaments across France between 2000 and 2003. In one case, he spiked the water bottle of the 25 year old tennis player Alexandre Lagardere, using the anti-anxiety drug Temesta, just before Lagardere was to play against Fauviau's son. Temesta can cause extreme drowsiness, and 
shortly after the match with Faviau's son Lagardere crashed his car and died. Fauviau confessed to the crime; investigators found traces of Temesta in Lagardere's body. ${ }^{2}$

We easily recognize bad sports parents when their behaviour is as morally wrong, such as in the examples above. Yet, to put the question positively: What makes a good sports parent? It is obvious that one should not act as Christoph Fauviau did, but what should a good sports parent do if his or her child's ${ }^{3}$ participation in sports raises ethical issues - and where it is not obvious what the morally right thing to do would be? For example, should a good sports parent respect their child's decision to take legal performanceenhancing medicine? Should a parent always be honest about his or her child's athletic skills? These issues might be described as falling within a grey area: they involve contentious questions about the ethics of the parentchild relationship in the context of sport.

The aim of this paper is to address the question 'What makes a good sports parent?' I find the question important for three reasons. Firstly, there are very few systematic and thorough ethical analyses of this subject. ${ }^{4}$ Moral reflection on sport is primarily concerned with the activities of the various athletes, trainers, coaches, judges, and organizations involved - not the parent-child relationship (see e.g. Boxhill 2002; Tamburrini \& Tännsjö 2000). Secondly, as a parent, it can be a very stressful experience to watch one's child play in an intense, tough sports match, especially if one believes that the child's opponent or the referee have treated one's child unjustly. In such situations, it is not easy to keep calm and make the best decisions. It is my hope that critical discussion of the different approaches to what makes a good sports parent will help the reader to think more productively about how to behave towards a child in the context of sport. Thirdly, the behaviour of parents, besides having an effect on the parents themselves, has an effect, for better or worse, on the well-being of the child. Studies show that parents are the primary cause in initiating children to participate in sport and encouraging them to enjoy it (Collins \& Barber 2006).

\section{What makes a good sports parent? Some practical responses}

Can we be more specific about what it is that makes someone a good sports parent? In what follows, I will first focus on what parents should do to encourage their children in a sports context before presenting and commenting on two specific measures that have been taken to combat bad behaviour. The first measure involves a 'non-interference principle' for sports parents. The example that I will comment on is known as a the strategy of 'quiet weekends' in which parents are either prohibited from attending games, or allowed to 
attend but not allowed to interfere verbally and by shouting and the like (Llewellyn 2001: 9). ${ }^{5}$ The second measure involves ethical guidelines that describe in a rather detailed manner how good sports parents ought to behave in specific situations.

\section{Winning is not all that matters}

The effects which participating in sports can have on a child can be used to explore what makes a good sports parent. Let me, somewhat briefly, mention three types of effects. First, psychologically, participating in sport can be great fun. Furthermore, children can develop qualities such as patience and concentration, and learn to control anger and use it in a constructive way. Second, sport can be very beneficial for physical health. It gives strength to muscles and the skeleton, and it improves motor skills and hand-eye coordination. Quite generally, it can improve health (Dencker \& Andersen 2008; Jago et al. 2008; Hasselstrøm et al. 2008). Third, socially, there is much for children to gain from sport. Ideally, children who participate in a sport will make new friends. They should learn to cooperate with their team mates (and hence value the efforts of others), and to compete within the limits of rules without cheating. The bad effects of sport are, of course, the opposite of all these three positives.

A good sports parent is aware of all the possible benefits and harm that participating in sport can have for the child; he or she will try to act in a way that promotes the benefits and limits the harms for the child (and others). A good sports parent wants their child not only to win, but to have a good time. However, equally importantly, a good sports parent teaches their child that there are many important values that one can learn from participation in sport: for instance, values that have nothing to do with winning but a great deal to do with being a 'fair player' or a 'good team-mate'. By contrast, when we observe bad sports parents, we see that the reason they behave badly is usually their one-eyed focus on whether or not their child wins a match or is selected to join a team.

\section{Quiet weekends}

With the various examples of sports parents acting badly in mind, one can easily come to the conclusion that parents ought not to interfere at all when children participate in sport. However, the idea behind quiet weekends is not that parents should never interfere. Of course, they should support their child in various ways - financially, emotionally, with transport, and so forth. Otherwise, we would probably have fewer children participating in youth sports. The idea is rather that good parents should not interfere by shouting or screaming at youth matches, as this is believed to cause many 
of the morally problematic cases observed during such matches. ${ }^{6}$ An example of this is when parents, by screaming, try to bully the opponents of their child. From these premises one can infer that a good sports parent is one who keeps quiet either by not attending the game or, if they do attend, by remaining silent.

However, the conclusion of this argument is problematic for at least two reasons. First of all, it seems unfair to say that, because some parents behave badly, all parents ought to be kept away from, or remain silent at, youth sports matches. This is not fair to the majority of the parents. It is like a government, in an effort to stop violence at big football matches, prohibiting all spectators from attending games. Only those spectators or parents who have a record of bad behaviour should be denied access to the grounds. Equally, there may be alternative methods of preventing the relevant parents from problematic shouting and the like - for instance, parental education through ethical guidelines or some kind of counselling.

Secondly, for most children it does not seem to be a good idea to ban parents from watching or shouting support during a game. Studies have shown that children perform better, participate more in sport, and experience less stress in competition if their parents support them by watching and cheering them on when they (the children) play a match or attend practice (Hoyle \& Leff 1997).

Apart from these obvious problems, the quiet weekend strategy is a nonstarter in dealing with most of the moral problems that sports parents face. The suggestion that a good sports parent is one who does not watch their child compete or who keeps quite during a match is not very helpful when we want more general guidance on the great variety of moral problems in the grey area. The rationale of quiet weekends has nothing to say about whether a parent ought to let his or her child participate in an important tournament when the child is slightly injured, for example. Let us now turn to the second measure.

\section{Ethical guidelines for sports parents}

The idea behind ethical guidelines for sports parents is to allow parents to be guided by ethical guidelines - or to oblige them to be so guided. Many youth sports organizations have tried to develop such guidelines in response to incidents like those mentioned at the beginning of this article. Let me present eight examples from the International Tennis Federation's publication Guidelines to Help the Parents of Young Tennis Players: ${ }^{7}$ 
1 A pat on the back or an unemotional word of encouragement is often sufficient as the player leaves the court. You can discuss the match when they are less emotional. AVOID forcing your child to talk with you immediately after a loss.

2 Let the coach decide how much your child should practice. AVOID criticising your child for failure to play more tennis, or forcing him to train.

3 AVOID over training and burnout.

4 Take injuries seriously and if in doubt consult a doctor. Don't ignore aches and pains and never force your child to play when injured.

5 Your child's welfare and well being is the most important thing. AVOID letting your child's tennis become more important to you than your child.

6 Try to be honest and consistent when communicating with your child about his tennis. AVOID lying.

7 Try to encourage your child to be independent and to think for himself. AVOID coaching from the sidelines.

8 Realise that children not only have the right to participate in tennis but also, to choose not to participate.

One advantage of these guidelines is that they can function as a sparring partner and give parents answers, or reminders, as to how to behave in sports situations that often test tennis parents and their children emotionally. For instance, the first of the guidelines seems to be a very good idea: by letting one's child cool off after a tennis match, one gives the child (and oneself) a chance to cope with the loss. Further, and probably more importantly, parents may save their child from listening to his or her parents' emotional, and perhaps, critical and harmful comments.

That the ITF guidelines (ITF 2000) have something to offer parents when confronted by moral problems in the grey area, is shown by another example. Although the guidelines do not directly determine whether a parent should allow a child to play an important match when slightly injured, they remind parents of two important matters bearing on their decision: consult a doctor to see how serious the injury is, and let no one force or manipulate the child to play the match. However, do such guidelines give a satisfying answer to the question of what makes a good sports parent? Well, sometimes they do and sometimes they do not. They point in a vague way at what a good tennis parent ought to do in certain specific situations, but what generally characterizes a good sports parent (or even a good tennis parent) is not made explicit. In the next section it will be suggested that, plausibly, two central values can be derived from the ITF guidelines and other similar guidelines. In rather more general terms, these values describe what a good parent (whether a sports parent or not) is.

However, for readers trained in philosophy, sociology, or some other academic discipline, I need first to mention some familiar philosophical objections to ethical guidelines: (i) the guidelines fail to give any guidance when they are in conflict with one another; (ii) the status and scope of guidelines are often too vague to allow them to be action-guiding; and (iii) in 
practice, guidelines cannot cover all situations (Bowie \& Duska 1989). Let me briefly illustrate these charges one by one.

Looking at the ITF guidelines, it is easy to imagine conflicts where it is not obvious what parents should do. Let me give two examples. First, if one as a sports parent follows guideline 3 ('Let the coach decide how much your child should practice'), one may well find oneself in conflict with guideline 4 ('Avoid over training and burnout'), for some coaches will, in effect, recommend over-training and burnout. Secondly, what happens if being honest with one's child (guideline 6) is in conflict with promoting his or her well-being (guideline 5)? Suppose that being honest about what one thinks of one's child's results would erode his or her well-being: what would happen then?

It is also easy to question the status and scope of some of the guidelines. How are we, for example, to interpret guideline 5: 'Your child's welfare and well-being is the most important thing. AVOID letting your child's tennis become more important to you than your child'? If that means that the wellbeing of the child is the most important thing altogether, then why is this only mentioned in the original text as guideline number 34 ? Again, the other half of the guideline makes one wonder whether the well-being of the child is the most important thing, all things considered, or whether it can be outweighed by concern for others. Finally, like the law, ethical guidelines cannot cover all the situations that one will be confronted by as a sports parent. For example, the ITF guidelines have nothing directly to say about the use of medical substances or methods in junior tennis.

In what follows I will not elaborate on this obvious line of criticism of ethical guidelines further. While such criticism has an important purpose in pinpointing shortcomings, to a certain extent it misses the mark. For the aim of ethical guidelines, in order to be readable and practically effective, they should be written in a non-technical language without too many provisos and definitions. Instead, I find it more interesting to step back a little, and see whether we can derive some of the essential values that run through such guidelines. These values reveal the virtues that people care about in the parent-child relationship (whether in a sports context or not) and provide reasons to choose one alternative course of action rather than another. The clarification of these values can be used (i) to reason about, and give justified answers to, problems not mentioned in the guidelines, and also (ii) to reason, and develop justified answers, when there is internal conflict among the various specific guidelines. So, in essence, I want to show how guidelines can help to address the more theoretical problems which they themselves raise. I shall concentrate on just two of the values running through the ITF (and other) guidelines. I shall present these, apply them, and critically discuss them. 


\section{Parental concern for the autonomy and well-being of the child}

Two moral values seem to run prominently through most guidelines in youth sports. These relate to the autonomy and well-being of the child. It seems reasonable to focus on guidelines 7, 8 , and the last part of 1 and 2, expressing concern for the autonomy of the child, and also guidelines 1,3 , 4,5 , and 6 , expressing concern for the well-being of the child. In order to discuss how these values might guide the sports parents confronted with problems in the grey area, I will now describe them in more detail. ${ }^{8}$

\section{Autonomy}

However, before I present a standard view of autonomy and some of the problems parents may face when they try to determine the autonomy of the child, I will briefly explain why it is reasonable to interpret some of the guidelines as expressing a concern for the child's autonomy. First of all, we should be aware of the possibility that guidelines 7 and 8 (and the latter part of 1 and 2) can be explained by reference to a libertarian outlook rather than an outlook that favours autonomy. On a libertarian view, all people have a right to decide what to do with their own bodies as long as they do not violate the rights of others. In the philosophical literature this element of libertarianism is called the 'self-ownership thesis' (Vallentyne 2009; Nozick 1974). On this interpretation, guidelines 7 and 8 advise that parents should never prevent their children from participating in a tournament if they (the children) want to do so, even if an injury is apparent - unless, of course, the participation violates the right of others. Further, the same kind of reasoning can be employed to argue that children should be allowed to take performance-enhancing drugs without interference from their parents. It should be clear from these examples that whether a person is autonomous or not is morally irrelevant - what matters is that no one should interfere with a decision unless it violate the rights others. It what follows it is taken for granted that parents should not be guided by this interpretation of guidelines 7 and 8 . The argument is that it sometimes seems morally right to prevent children from making a decision (autonomous or not) regarding the use of their own body, e.g. in order to promote their net or long-term welfare. So, because of this normative observation, it seems reasonable to claim that we should stick to another interpretation of guidelines 7 and 8 .

One obvious choice is that we should respect or promote a child's decision, if the child is autonomous. ${ }^{9}$ Yet when is that the case? On a standard definition of autonomy, whether a person is autonomous requires, roughly speaking, the following: (i) that he or she is well-informed about the relevant issues (e.g. risks to health); (ii) that he or she is a competent decision 
maker; and (iii) that his or her decision is not a result of undue influence (e.g. coercion) (Brock \& Buchanan 1989). The claim that we should respect or promote autonomous decisions can be justified if we accept the plausible claim that autonomous decisions makers are better than non-autonomous decision makers at deciding what is good for them and others. However, on this interpretation, a parent could be entitled to interfere with an injured child's decision to participate if the child is not autonomous and the parent judges that participation would not be good for the child's well-being in the long run.

One practical problem that parents are confronted by when they want to respect or promote the autonomy of their children is that of determining whether their child is autonomous. It would be inadvisable to try to describe in detail what the complex condition of autonomy involves here. I will therefore focus on just one component of autonomy - namely, that of being a competent decision maker.

In the standard psychological and philosophical literature on the subject, a competent decision maker is an individual who is able to communicate and understand information, who has the ability to reason about the consequences of making a certain choice, and who can compare the ways in which the various alternatives will affect his or her own good and the good of others. If an individual lacks any of these abilities when making a decision, that individual is not a competent decision maker. Take the example of a child at the age of 10 years who loves to play soccer, and who decides to play in a soccer tournament even though that child knows that he or she has mononucleosis. Mononucleosis is an infectious disease that can cause fever and a swollen spleen. To combat this disease the patient must not engage in too much physical activity, as this can cause the spleen to burst, with death as a probable consequence. It is clear from this example that the child's decision is not that of a competent individual. Surely, either he or she has not received the relevant information, or is not able to understand the information, or cannot reason in the right sense - as he or she has clearly chosen to act in a way that cannot be in his or her own (or the parents') interests. However, when we move away from the more extreme cases such as this, in which it is fairly easy to determine the incompetence of the child, it can be difficult to estimate whether or not a minor is a competent decision maker.

Furthermore, like all parents, sports parents must take the following considerations into account when they try to evaluate the competence of their children. First of all, the competence of a child is relative to a specific decision. Like an adult, a child can be an incompetent decision maker in one situation and competent in another. For instance, if a child is injured during a tough and important sports competition, he or she might display incompetence (due to being under physical and emotional stress) when deciding to carry on playing. On the other hand, that same child might have been 
competent when, before a match, and in more calm surroundings, he or she was injured in a similar way and decided not to play. Alternatively, the child may be incompetent when it comes to deciding whether it is good to take caffeine in order to perform better, but competent enough to choose what basketball club he or she should play for. Secondly, (as already hinted) apart from these individual differences, there is no doubt that children's competence will also vary with their age and development. A 14 year old boy will typically be a competent decision maker in a wider range of situations than a 9 year old boy.

How should parents be guided by concern for their child's autonomy? Let me try to answer this question by discussing how much value the respect or promotion of autonomy should be accorded. As a starting point, it seems obvious that parents should not opt for the extreme view that autonomy has absolute value - the view, that is, that parents should always respect or promote the decisions made by their child (if autonomous) in a sports context. Let us call this view 'anti-paternalism'. For, although many minors are so mature that it would seem implausible to exclude them from the decisionmaking process altogether, their decisions are in certain situations so questionable that even if they are made autonomously they should be overruled. Thus, unless extraordinary circumstances arise, if one's child is planning to intentionally cheat an opponent or take an illegal performance-enhancing drug, one ought to prevent him or her from doing so. Furthermore, one should do so even if one believes that the decision was autonomous.

To summarize, a plausible account of when to respect or promote the autonomy of one's child will probably involve a moderate position in which paternalism has a place. Yet what exactly is a paternalistic act, and when should parents act paternalistically? Although there is no agreed conception of paternalistic action, the core idea seems to be something akin to the following: an act of A's is paternalistic to B if (i) A does something to B that $B$ would prefer A not to do, and (ii) A acts that way because A believes that $\mathrm{B}$ will thereby be made better off. ${ }^{10}$ Thus, if, against the child's wishes, a parent prevents the child from participating in a tournament, and if this is done in the belief that the child will be better off not playing, we have a paternalistic act. One consideration favouring paternalism, then, is this: the fact that the child will be better off (e.g. in terms of well-being) after a paternalistic intervention suggests that it is morally right to be paternalistic. This seems obvious: Why respect or promote an autonomous act A (or a nonautonomous act) if, for example, some are worse off and no one is better off because of A?'

Paternalism seems to provide us with reasons to act in situations where guidelines throw up internal conflicts or have nothing to say. For instance, the paternalistic position can explain why in some situations a parent should not be honest with their child about his or her athletic abilities, even 
if the child wants the parent to be honest. The explanation will be that, by being honest in this instance, the parent will harm the child. Again, paternalism can explain why a parent ought to let an eager but injured child play if the injury is not too severe and the attendant risk of there being a harmful effect on the child is very low.

However, before we move on, let me mention some important reminders that a morally defensible version of paternalism needs to take into account. First, before sports parents make a decision on behalf of their child (whether that child is autonomous or not), they ought to take into account the child's view of the issue in question. It should come as no surprise that children sometimes have knowledge of themselves and conceptions of what is good that are not readily accessible to their parents. For instance, a child may be best placed to know how harmful, in their personal experience, an injury is. Secondly, if a child's decision is of the sort that has little impact on his or her well-being - because, for instance, it is about what clothes to wear when participating in sports, or about whether to take a few extra vitamins in order to perform better, or about playing a match with a headache. There are several reasons why parents should not attempt to intervene over these types of decision. First of all, costs will usually be connected with the overturning of a decision. Generally speaking, having one's decisions overruled is not a welcome event, and it may put stress on the relationship between child and parent. Secondly, if we believe that autonomy is valuable, and if we accept that an individual can only develop autonomy by gradually deciding, more and more often, what to do independently of his or her parents, we have reason to hesitate before acting paternalistically in such situations.

With these considerations in mind we are in a position to state some guidelines of what we might call 'required paternalism. Three things seem to be important. For parents to act paternalistically in an ethically acceptable way, they must, with sufficient certainty, know (i) that the child's own decision will make the child worse off than the alternative, imposed decision; (ii) that the paternalistic intervention will make the child better off; and (iii) that the paternalistic act would not have considerable negative effect on others (e.g. the parents or other children).

These guidelines are, of course, general, and to a certain extent imprecise, and each parent therefore will need, on each occasion of decision, to make an individual evaluation of whether or not a paternalistic act is required. However, the value of the guidelines is that they clearly identify what parents should be concerned about when they consider acting paternalistically towards their children. The definition and evaluation of welfare which is so central in the paternalistic position - will be dealt with in the next section. For now, I want to raise another issue: Why should parents, and not, for example, a coach, decide what is to be done? 
In the context of sport, when we talk about paternalism in the parentchild relationship, it seems reasonable to ask whether it should only (or primarily) be the parent who ought to act paternalistically. Until now it has been taken for granted that parents should decide on behalf of their children - at least, in cases where the child is not a competent decision maker, or is a competent decision maker but might make decisions that would threaten his or her own good. However, why should it be assumed that parents should occupy this role? Many would say that it is nothing more than common sense to insist that parents should have the last word on whether their child should participate in a sport, or how much time the child should be allowed to spend on practice, or whether or not the child will attend a tournament. This resembles the intuitive response most people have when they consider decisions concerning their child's medical treatment or whether the child should be a research subject. The response is that the parents, not others, ought to decide whether their children are treated or participate in medical research. ${ }^{11}$ The reason that parents should have the last say on decisions made by their children is that, of all the competent adults around the child (coaches, trainers, judges), parents will normally know the child best and have the interests of the child foremost in mind. Although the two examples mentioned at the outset of this paper clearly show that this is not always the case, I will take it for granted that it is usually the case.

However, to support the idea that parents ought to have this kind of decision-making authority in a particular case, we need to presuppose that the parents in question are not just competent decision makers, but also informed about the facts bearing on a decision, and we must further assume that these parents make their decisions on a voluntary basis, free from undue influence. In all this, we are imagining that the parents are autonomous. Everything else being equal, paternalistic decisions will have an increased chance of leading to bad outcomes if the parents do not know whether their child wants to participate, if they do not understand how long the competition will take, if they fail to see what kind of competition is in prospect, or if they are uninformed about where the competition will take place, or about whether friends and family can attend and watch. Undoubtedly, there will generally be a justifiable outcry if parents are forced, by the coach, for instance, to let their child participate against the will of his or her parents and the will of the child. Yet if parents are not the best caretakers of their children's well-being, there is a least a reason to overrule their decision. However, my aim in this article has been to clarify what a good sports parent is, not to explain what to do when parents act in a way that threatens the well-being of their child or others. ${ }^{12}$ These observations, together with points made about paternalism, bring us to the second important value in the parent-child relationship: the well-being of the child. 


\section{Well-being}

Let us take the following for granted: all parents ought to accept that one important moral obligation parents have to their children is to do what best promotes the well-being of their children. In the present context, this amounts to the following, admittedly somewhat vague ideal: everything being equal, if his or her participation in a sport best promotes the wellbeing of one's child, one ought to support that participation, and if not, one ought to make sure that one's child does not participate.

The 'everything being equal' clause is designed to ensure that this assertion is not too partial and does not imply that the only subject of a parent's moral obligation is the child. Parents, of course, have moral obligations to people other than their children in sport. It therefore seems obvious that sports parents sometimes ought to act in such a way that they do not do what is best for their child. This might be the case where, for instance, a parent chooses to promote the well-being of others (e.g. himself or another child) while knowing that this will lead to only a small loss in terms of wellbeing for his or her own child. For instance, a child involved in sport might benefit from participation in a tournament that is far away from home. This may be contrary to the interests of the other family members if the child's participation implies that that the family cannot take a summer holiday together, perhaps because they cannot afford to do so.

Certainly, this ideal will need to be made more precise if it is to be used as a parental guide. In what follows, I will try to provide rough answers to the following questions in a way that renders the child's best interest view more applicable as a guiding principle. First, what is meant by 'best' in 'best promotes'? Second, if we agree that paternalism is required in order to safeguard the well-being of the child, how do we estimate well-being?

The term 'best' should be understood in connection with an all things considered clause. In order to determine whether or not one's child should, for example, enter a soccer tournament, one should compare the expected net benefit of each of the alternative options (e.g. of entering the tournament, another tournament, or no tournament) with the probability that each option will produce the relevant benefit. One could then determine what option one expects will best promote the well-being of one's child. So, the mere fact that playing soccer, for example, benefits one's child is not sufficient to show that soccer playing would be in the best interest of the child. There may be another option that would have a greater net benefit - and ideally one should choose the act which benefits one's child's well-being most. Moreover, the mere fact that one's child would be harmed by losing a soccer match is not sufficient to show that it would be in the best interest of the child to be prevented (by the parent) from playing soccer. Soccer may still be the activity that, all things considered, is in the best interest of the 
child: it may be the case that playing soccer usually benefits the child a great deal, and more so than other activities.

I cannot enter into questions about the nature of well-being here. ${ }^{13} \mathrm{I}$ have space only to mention that parents who are considering acting paternalistically can choose to view the well-being of their child from one of two perspectives. A parent can act paternalistically if he or she acts in a way which from his or her viewpoint will benefit the child. So, in evaluating the well-being of the child who wishes to play soccer, for example, a father will try to imagine (or recall) what it is like to play soccer, and if the father does not like soccer, he will probably estimate that his son or daughter would not benefit from participation in this sport. Let us call this view 'parent-centred paternalism. However, it seems far more appropriate to use the child's own experiences as a basis for evaluation of the child's well-being: it is not the father, but the child, that may be playing soccer. It may be the case that the child would love to play soccer, even though the child's father strongly dislikes it. Let us call this far more plausible view 'child-centred paternalism'.

\section{Conclusion}

These reflections on what makes a good sports parent permit the following conclusions to be drawn. First of all, good sports parents do not only pay attention to winning. Instead, they pay significant attention to all of the other benefits a child can gain through sport (e.g. fun, health, teamwork). Good sports parents are also aware that it is hard work being a good sports parent, because it can be emotionally stressful to watch one's own child in a tough match. Such parents must be willing to take on this challenge. Secondly, in order to stay good, the good sports parent will be guided or influenced by ethical guidelines. In that way it will be possible to learn about the ethics and psychology of good parenting. Thirdly, where there are no guidelines, or if the guidelines do not apply or are in conflict with one another, parents should have recourse to the values that run through the guidelines: they should be responsive to a concern for the autonomy and well-being of the child. However, if autonomy and well-being conflict - because it is only possible to promote well-being by disrespecting autonomy - parents should favour what I have called 'required paternalism'. It should be recalled that the aim of my article has not been to give clear-cut answers to moral challenges in the grey area, but rather to specify how we should reason about such problems. ${ }^{14}$ 


\section{Notes}

1 Hockey Dad from Hell, www.vanceholmes.com/cort/trial_junta.html (2007).

2 Prison for Zealous Tennis Dad, www.dwbthenewstribune.com/news/nationworld/ story/5 578 359p-5 017 819c.html

3 By 'children' I refer to children who are old enough to participate in sport, which usually means children aged between 5 and 18 years old.

4 Exceptions include Dixon (2007).

5 For this strategy see also 'Silent Saturdays and Oaths' in Newshour, www.pbs.org/ newshour/extra/features/july-dec00/solutions.htlm

6 The strategy of quiet weekends have been practiced in several places in e.g. the US. See http://www.positivecoach.org/SubContent.aspx?id=1556

7 I reproduce this selection verbatim. The original publication actually contains 49 guidelines.

8 Quiet weekends seem to be motivated by both values.

9 Usually philosophers distinguish between respecting and promoting a value. Parent $\mathrm{P}$ respects child C's autonomous decision to do $\mathrm{X}$ if $\mathrm{P}$ does not prevent $\mathrm{C}$ from doing $\mathrm{X}$ (e.g. by undue influence such as coercion). Parent $\mathrm{P}$ promotes child C's autonomous decision to do $\mathrm{X}$ if $\mathrm{P}$ acts in a way that makes $\mathrm{X}$ happen. However, when we talk about parents respecting children's decisions, non-interference does not seem to be all that matters. For example, if 'Paul' wants to play soccer his father might prevent him from playing by not helping with transportation or money.

10 This is very similar to Dworkin's thinking (2005).

11 This does not mean that parents ought to make such decisions in isolation, but quite the contrary. Most parents both seek and ought to seek information from experts. The point is just that parents ought to have the final word after they have been informed.

12 However, a good sports parent may also be characterised as a person who intervenes when another sports parent is acting against a child's interests.

13 See e.g. Griffin (1986) and Sumner (1996) for treatment of the nature of well-being.

14 First of all, thanks to Julian Savulescu who suggested me to write an article on this subject. Thanks also for his and the participants valuable comments at the James Martin 21 century School lecture in Oxford November 2007. Thanks also to Jesper Ryberg, Frej Klem Thomsen, Jakob v. H. Holterman for valuable comments. Finally, thanks to the Uehiro Centre for Practical Ethics (Oxford University) for their hospitality during the autumm of 2009 which gave me the perfect work environment to finish a first version of this paper.

\section{Literature}

Bowie, N.E. \& Duska R. (1989) Business Ethics. New Jersey: Prentice Hall.

Boxill, B. (2002) Sports Ethics: An Anthology. Oxford: Blackwell Publishing.

Brock, D.W. \& Buchanan, A.E. (1989) Deciding for Others. Cambridge, UK: Cambridge University Press.

Collins, K. \& Barber, H. (2006) Female Athletes' Perceptions of Parental Influences. Journal of Sport Behaviour, 28 (4), pp. 295-314. 
Dencker, M. \& Andersen, L.B. (2008) Health-related aspects of objectively measured daily physical activity in children. Clinical physiology and functional imaging, 28 (3), pp. 133-144.

Dixon, N. (2007) Sport, Parental Autonomy, and Children's Right to an Open Future. Journal of the Philosophy of Sport, XXXIV (2), pp. 147-159.

Dworkin, G. (2005) Paternalism. Stanford Encyclopaedia of Philosophy. Accessed February 2010 from http://plato.standford.edu/entries/paternalism

Feldman, F. (2004) Pleasure and the Good Life. Oxford: Oxford University Press.

Griffin, J. (1986) Well-being: Its meaning, measurement and moral importance. Oxford: Clarendon Press.

Hasselstrøm, H.A., Karlsson, M.K., Hansen, S.E., Grønfeldt, V., Froberg, K. \& Andersen, L.B. (2008) A 3 year Physical Activity Intervention Programme increases the Gain in Bone Mineral and Bone Width in Prepubertal Girls but not in Boys; The Prospective Copenhagen Schoool Child Intervention Study (CoSCIS). Calcified Tissue International, 83 (4), pp. 243-250.

Hoyle, R.H. \& Leff, S.S. (1997) The role of parental involvement in youth sport participation and performance. Adolescence, 32, pp. 233-243.

ITF (2000) Being a Better Tennis Parent: Guidelines to help the parents of young tennis players. London: The International Tennis Federation.

Jago, R., Wedderkopp, N., Kristensen, P.L., Møller, N.C., Andersen, L.B., Cooper, A. \& Froberg, K. (2008) Six-year change in youth physical activity and effect on fasting insulin and HOMA-IR. American Journal of Preventive Medicine, 35 (6), pp. 554-560.

Llewellyn, J. (2001) Let'em Play. Athens, US: Longstreet Press Inc.

Nozick, R. (1974) Anarchy, State, and Utopia. New York: Basic Books.

Sumner, W. (1996) Welfare, Happiness, and Ethics. Oxford: Oxford University Press.

Tamburrini, C. \& Tännsjö, T. (2000) Values in Sport - Elitism, Nationalism, Gender Equality and the Scientific Manufacture of Winner. London \& New York: Spoon Publishing.

Vallentyne, P. (2009) Libertarianism. Standford Encyclopaedia of Philosophy. Downloaded December 2009 from http://plato.standford.edu/entries/paternalism 